\title{
Albumin-to-Alkaline Phosphatase Ratio Associates with Good Prognosis of Hepatitis B Virus-Positive HCC Patients
}

This article was published in the following Dove Press journal: OncoTargets and Therapy

\author{
Qun $\mathrm{Li}^{1, *}$ \\ Zhuozhen Lyu',* \\ Liguang Wang $\mathbb{D}^{2, *}$ \\ Feifei $\mathrm{Li}^{1}$ \\ Zhen Yang' \\ Wanhua Ren' \\ 'Department of Infectious Disease, \\ Shandong Provincial Hospital Affiliated to \\ Shandong University, Jinan, Shandong \\ 25002I, People's Republic of China; \\ ${ }^{2}$ Department of Oncology, Shandong \\ Provincial Hospital Affiliated to Shandong \\ First Medical University, Shandong Provincial \\ Hospital Affiliated to Shandong University, \\ Jinan, Shandong 25002I, People's Republic \\ of China
}

*These authors contributed equally to this work
Correspondence: Wanhua Ren Department of Infectious Disease, Shandong Provincial Hospital Affiliated to Shandong University, Jinan, Shandong 25002I, People's Republic of China Email renwanhua00I@I63.com
Purpose: The aim of this study was to investigate the prognostic significance of preoperative AAPR in hepatitis B virus-related hepatocellular carcinoma patients after curative hepatectomy.

Patients and Methods: A total of 221 patients with hepatitis B virus-related HCC patients who received curative liver resection were included. After propensity matching analysis, 188 patients were enrolled in the final analysis. COX regression analyses were used to analyze the prognosis value of AAPR and other prognostic factors. The overall survival (OS) and recurrence-free survival (RFS) curves were constructed and compared between different groups.

Results: The optimal cutoff of AAPR was defined as 0.40 with X-tile software. According to cutoff value, patients were divided into low-AAPR group $(\leq 0.40)$ and high-AAPR group $(>0.40)$. The cumulative 1-, 3-, and 5-year OS rates were $97.1 \%, 78.2 \%$, and $67.3 \%$ in patients with AAPR $>0.40$ group, respectively, which were significantly higher than those in the $\mathrm{AAPR} \leq 0.40$ group $(80.2 \%, 54.4 \%$, and $40.1 \%$, respectively) $(\mathrm{P}<0.001)$. In the multivariate COX regression analysis, AAPR, tumor number, ascites, and portal vein tumor thrombus (PVTT) were independent risk factors for OS and RFS.

Conclusion: AAPR shows promise as a reliable prognostic factor in patients with hepatitis $\mathrm{B}$ virus-related $\mathrm{HCC}$ after curative hepatectomy, which could be used as a routine inspection of HCC patients before surgery.

Keywords: albumin-to-alkaline phosphatase ratio, prognosis, hepatitis B virus, hepatocellular carcinoma

\section{Introduction}

Hepatocellular carcinoma (HCC) is one of the most common human malignancies, and the second leading cause of cancer-related death in men in developing countries. ${ }^{1}$ On a greater scale, the high incidence of HCC in Asia reflects the incidence of hepatitis $\mathrm{B}$ virus (HBV) infection, where more than $5 \%$ of the population have been infected chronically. ${ }^{1}$ However, in the Western hemisphere, hepatitis $\mathrm{C}$ virus (HCV) infection, alcoholism and obesity are additional risk factors for $\mathrm{HCC}^{2}$ At the present moment, the most commonly used therapeutic options for HCC patients are liver resection and liver transplantation. ${ }^{3}$ Although liver transplantation has developed in recent years, its application in China has been limited by the shortage of donors and expensive price of operation. As defined by the BCLC staging system, surgical resection remains the first-line treatment for patients with the best results. ${ }^{4}$ 
Furthermore, due to the high recurrence and metastasis, the long-term prognosis after hepatectomy remains poor. Therefore, exploring simple and reliable predictors for identifying patients with poor prognosis would be a crucial step for better treatment.

Current evidence demonstrates clinicopathological factors, such as tumor diameter, tumor capsule and vascular invasion have been confirmed to be associated with early intrahepatic recurrence of solitary $\mathrm{HCC}$ after curative liver resection. ${ }^{5}$ However, these clinical tumor parameters could only partially explain the prognostic heterogeneity of HCC. In recent years, some combined indexes have also been proven to be predictors for HCC patients with resection, such as lymphocyte-to-monocyte ratio (LMR), platelet-tolymphocyte ratio (PLR), and neutrophil-to-lymphocyte ratio (NLR). ${ }^{6-8}$ In recent studies, Albumin-alkaline phosphatase ratio (AAPR), an indicator that combines albumin and alkaline phosphatase has been identified to be a novel indicator for forecasting the prognosis of HCC. Cai et al identified that the AAPR was an independent factor for OS in advanced HCC patients without receiving standard anti-cancer therapies. ${ }^{9}$ Their team also confirmed AAPR as an independent prognostic factor in HCC patients treated with TACE. ${ }^{10}$

However, to the best of our knowledge, there have been few studies exploring the prognostic value of AAPR in HBV-related HCC patients who received curative resection. ${ }^{11}$ Therefore, our study was performed to verify the prognostic significance of AAPR in HBVrelated HCC patients who received curative liver resection. In this retrospective study, both overall survival (OS) and tumor recurrence-free survival (RFS) were analyzed.

\section{Patients}

A total of $221 \mathrm{HBV}$-related HCC patients in Shandong Provincial Hospital who underwent liver cancer resection and were initially treated with curative hepatectomy between 2010 and 2015 were included in the study. Patients who were included had complete removal of the tumor, which we defined as curative liver resection. The exclusion criteria of the patients were as follows: (1) Patients who underwent preoperative therapy, such as transarterial chemoembolization, radiofrequency ablation, or percutaneous ethanol injection; (2) HCC combined with other tumors or coexistent hematological disorders; (3) patients without medical information or incomplete information after follow-up; and (4) Cirrhotic patients with a clinical severity of grade $\mathrm{C}$ on the Child-Pugh Cirrhosis scale.
The study was approved by the Ethics Committee of Shandong Provincial Hospital. All included patients provided signed consent for participation in the study, and written informed consent for the use of clinical data was obtained at the time of surgery. Clinical information was obtained and reviewed through medical archives. This study was conducted in accordance with the Declaration of Helsinki.

\section{Data Collection}

Demographic and clinical data included age, gender, liver cirrhosis, lymph nodes metastasis, tumor size, tumor number, ascites and portal vein tumor thrombus (PVTT) were collected. The calculation of AAPR of all subjects was based on preoperative blood value. Routine examination of these 221 HCC patients, including ultrasonography (US), computed tomography (CT), magnetic resonance imaging (MRI) and blood biochemical examination were performed within 1 week before surgery.

\section{Follow-Up}

After surgery, patients were followed up with an interval of 3 months for the first 2 years and every 6 months thereafter. During the follow-up visits, routine physical examination, liver function tests, serum AFP level, and imaging examinations were conducted. When suspected of recurrence, abdominal enhanced computed tomography (CT) scan, magnetic resonance imaging (MRI), and PETCT were selectively performed. Patients with confirmed recurrence received further treatment, such as the second surgical resection, transarterial chemoembolization, or radiofrequency ablation. OS and RFS were used as primary end points. OS was calculated from the date of operation to the date of death or the date of last followup. RFS was calculated from the date of operation to the date of first recurrence or the date of last follow-up (for the patients without recurrence).

\section{Statistical Analysis}

Statistical analysis was performed using SPSS 24.0 software (SPSS, Chicago, IL, USA). The optimal cutoff of AAPR was obtained through X-tile software using minimum $\mathrm{P}$ value method. ${ }^{12}$ Categorical data were analyzed by a $\chi^{2}$ test or Fisher's exact test. The propensity score matching (PSM) was performed based on age, gender, liver cirrhosis, PVTT, ascites, tumor number, tumor size and lymph nodes. Then, a 1:1 match between the AAPR $>0.40$ group and $\mathrm{AAPR} \leq 0.40$ group was performed (caliper $=0.2$ ). Moreover, 
the matching algorithm was nearest neighbor matching, and the estimation algorithm was logistic regression. The cumulative OS and RFS rates were assessed by the Kaplan-Meier method, and the difference between the two groups was evaluated by log-rank test. Cox proportional hazards regression models with corresponding 95\% Cis were used for univariate and multivariate analysis of prognostic factors affecting OS and RFS. A p-value of 0.05 was considered to be statistically significant.

\section{Results}

\section{Clinicopathological Characteristics After PSM}

After selection, $221 \mathrm{HBV}$-related HCC patients were included in this retrospective cohort study. As far as we know, clinicopathological factors, such as tumor diameter, PVTT, have been confirmed to be associated with early intrahepatic recurrence of solitary $\mathrm{HCC}$ after curative liver resection. Therefore, we performed a propensity matching analysis (PSM) to reduce data bias. After the 1:1 PSM, 188 patients were enrolled in the final analysis (33 patients were not matched and excluded; Table 1). Among them, 161 patients were males and 27 were females, with a maleto-female ratio of 5.96:1. The median age of the entire cohort was 52.3 years (range, 22-77years). The median follow-up duration was 46.5 months. Baseline clinicopathologic characteristics are shown in Table 1.

\section{The Optimal Cutoff Value for AAPR}

The optimal cutoff value of AAPR for predicting OS was established by X-tile 3.6.1 software, and results from $\mathrm{X}$-tile analysis revealed that the optimal cutoff point for the AAPR level was 0.40. Subsequently, according to the cutoff value, $94(50 \%)$ patients were included in the highAAPR group (AAPR $>0.40)$ and $94(50 \%)$ patients were included in the low-AAPR group (AAPR $\leq 0.40$ ).

Table I Baseline Characteristics for Patients with High and Low AAPR Before and After PSM

\begin{tabular}{|c|c|c|c|c|c|c|}
\hline & \multicolumn{2}{|c|}{ Before PSM } & \multirow[t]{2}{*}{$P$ value } & \multicolumn{2}{|l|}{ After PSM } & \multirow[t]{2}{*}{$P$ value } \\
\hline & AAPR $\leq 0.4$ & AAPR $>0.4$ & & AAPR $\leq 0.4$ & AAPR $>0.4$ & \\
\hline \multicolumn{7}{|l|}{ Age, Year } \\
\hline$\geq 60$ & 29 & 30 & 0.209 & 27 & 29 & 0.750 \\
\hline$<60$ & 95 & 67 & & 67 & 65 & \\
\hline \multicolumn{7}{|l|}{ Gender } \\
\hline Male & 107 & 83 & 0.533 & 79 & 82 & 0.878 \\
\hline Female & 17 & 14 & & 15 & 12 & \\
\hline \multicolumn{7}{|l|}{ Liver Cirrhosis } \\
\hline Yes & 22 & 21 & 0.466 & 17 & 20 & 0.582 \\
\hline No & 102 & 76 & & 77 & 74 & \\
\hline \multicolumn{7}{|l|}{ Lymph Nodes } \\
\hline Yes & 17 & 3 & 0.006 & 8 & 3 & 0.120 \\
\hline No & 107 & 94 & & 86 & 91 & \\
\hline \multicolumn{7}{|l|}{ PVTT } \\
\hline Yes & 103 & 86 & 0.241 & 78 & 83 & 0.352 \\
\hline No & 21 & II & & 16 & II & \\
\hline \multicolumn{7}{|l|}{ Ascites } \\
\hline Yes & 96 & 81 & 0.394 & 75 & 79 & 0.491 \\
\hline No & 28 & 16 & & 19 & 15 & \\
\hline \multicolumn{7}{|l|}{ Tumor Number } \\
\hline Single & 105 & 89 & 0.381 & 81 & 87 & 0.442 \\
\hline Multiple & 19 & 8 & & 13 & 7 & \\
\hline \multicolumn{7}{|l|}{ Tumor Size } \\
\hline$>5 \mathrm{~cm}$ & 55 & 68 & $<0.001$ & 50 & 62 & 0.075 \\
\hline$\leq 5 \mathrm{~cm}$ & 69 & 29 & & 44 & 32 & \\
\hline
\end{tabular}




\section{Prognostic Factors Associated with OS and RFS}

Our study aimed to determine the factors affecting OS and RFS. Thus, following univariate analysis, AAPR, ascites, tumor number, tumor size, and PVTT were determined to be prognostic factors associated with OS. Multivariate regression analysis demonstrated that AAPR, ascites, tumor number, PVTT were independent risk predictors of OS. Univariate and multivariate analysis of factors affecting OS is shown in Table 2. With regard to RFS, univariate analysis indicated that AAPR, ascites, tumor size, tumor number, and PVTT was significant predictors of RFS. The factors mentioned above were assessed using multivariate COX regression analysis revealing that AAPR, ascites, tumor number, and PVTT could be independent predictors of poor RFS for HBV-

Table 2 OS Univariate and Multivariate Cox Regression After PSM

\begin{tabular}{|c|c|c|c|c|}
\hline \multirow[t]{2}{*}{ Variables } & \multicolumn{2}{|c|}{ Univariate Analysis } & \multicolumn{2}{|c|}{ Multivariate Analysis } \\
\hline & HR $(95 \% \mathrm{Cl})$ & $P$ value & HR $(95 \% \mathrm{Cl})$ & $P$ value \\
\hline $\begin{array}{l}\text { Age (Year) } \\
\qquad 60 \text { vs }<60\end{array}$ & $\begin{array}{l}1.269 \\
(0.805-2.000)\end{array}$ & 0.306 & & \\
\hline $\begin{array}{l}\text { Gender } \\
\text { Male vs female }\end{array}$ & $\begin{array}{l}0.640 \\
(0.320-1.278)\end{array}$ & 0.206 & & \\
\hline $\begin{array}{l}\text { AAPR } \\
\quad>0.4 \text { vs } \leq 0.4\end{array}$ & $\begin{array}{l}0.032 \\
(0.007-0.153)\end{array}$ & $<0.001$ & $\begin{array}{l}0.037 \\
(0.007-0.186)\end{array}$ & $<0.001$ \\
\hline $\begin{array}{l}\text { Liver Cirrhosis } \\
\text { Yes vs no }\end{array}$ & $\begin{array}{l}1.389 \\
(0.768-2.5 \mathrm{II})\end{array}$ & 0.277 & & \\
\hline $\begin{array}{l}\text { PVTT } \\
\text { Yes vs no }\end{array}$ & $\begin{array}{l}2.936 \\
(1.747-4.932)\end{array}$ & $<0.001$ & $\begin{array}{l}2.561 \\
(1.489-4.404)\end{array}$ & 0.001 \\
\hline $\begin{array}{l}\text { Ascites } \\
\text { Yes vs no }\end{array}$ & $\begin{array}{l}1.617 \\
(1.060-2.466)\end{array}$ & 0.026 & $\begin{array}{l}1.474 \\
(1.089-2.220)\end{array}$ & 0.045 \\
\hline $\begin{array}{l}\text { Tumor Number } \\
\text { Multiple vs single }\end{array}$ & $\begin{array}{l}1.855 \\
(1.287-2.673)\end{array}$ & 0.001 & $\begin{array}{l}1.899 \\
(1.318-2.736)\end{array}$ & 0.001 \\
\hline $\begin{array}{l}\text { Tumor Size }(\mathrm{cm}) \\
>5 \text { vs } \leq 5\end{array}$ & $\begin{array}{l}2.022 \\
(1.312-3.116)\end{array}$ & 0.001 & $\begin{array}{l}1.492 \\
(0.942-2.364)\end{array}$ & 0.088 \\
\hline $\begin{array}{l}\text { Lymph Nodes } \\
\text { Metastasis } \\
\text { Yes vs no }\end{array}$ & $\begin{array}{l}1.179 \\
(0.477-2.912)\end{array}$ & 0.721 & & \\
\hline
\end{tabular}

Table 3 RFS Univariate and Multivariate Cox Regression After PSM

\begin{tabular}{|c|c|c|c|c|}
\hline \multirow[t]{2}{*}{ Variables } & \multicolumn{2}{|c|}{ Univariate Analysis } & \multicolumn{2}{|c|}{ Multivariate Analysis } \\
\hline & HR $(95 \% \mathrm{Cl})$ & $P$ value & HR $(95 \% \mathrm{Cl})$ & $P$ value \\
\hline $\begin{array}{l}\text { Age (Year) } \\
\qquad 60 \text { vs }<60\end{array}$ & $\begin{array}{l}1.223 \\
(0.810-1.847)\end{array}$ & 0.338 & & \\
\hline $\begin{array}{l}\text { Gender } \\
\text { Male vs female }\end{array}$ & $\begin{array}{l}0.700 \\
(0.383-1.280)\end{array}$ & 0.247 & & \\
\hline $\begin{array}{l}\text { AAPR } \\
\qquad>0.4 \text { vs } \leq 0.4\end{array}$ & $\begin{array}{l}0.065 \\
(0.016-0.260)\end{array}$ & $<0.001$ & $\begin{array}{l}0.080 \\
(0.019-0.328)\end{array}$ & $<0.001$ \\
\hline $\begin{array}{l}\text { Liver Cirrhosis } \\
\text { Yes vs no }\end{array}$ & $\begin{array}{l}1.101 \\
(0.668-1.813)\end{array}$ & 0.706 & & \\
\hline $\begin{array}{l}\text { PVTT } \\
\text { Yes vs no }\end{array}$ & $\begin{array}{l}2.431 \\
(1.480-3.992)\end{array}$ & $<0.001$ & $\begin{array}{l}2.054 \\
(1.221-3.456)\end{array}$ & 0.007 \\
\hline $\begin{array}{l}\text { Ascites } \\
\text { Yes vs no }\end{array}$ & $\begin{array}{l}1.655 \\
(1.114-2.458)\end{array}$ & 0.013 & $\begin{array}{l}1.513 \\
(1.026-2.231)\end{array}$ & 0.036 \\
\hline $\begin{array}{l}\text { Tumor Number } \\
\text { Multiple vs } \\
\text { single }\end{array}$ & $\begin{array}{l}1.797 \\
(1.258-2.566)\end{array}$ & 0.001 & $\begin{array}{l}1.817 \\
(1.274-2.590)\end{array}$ & 0.001 \\
\hline $\begin{array}{l}\text { Tumor Size }(\mathrm{cm}) \\
>5 \text { vs } \leq 5\end{array}$ & $\begin{array}{l}1.806 \\
(1.222-2.670)\end{array}$ & 0.003 & $\begin{array}{l}1.429 \\
(0.943-2.166)\end{array}$ & 0.092 \\
\hline $\begin{array}{l}\text { Lymph Nodes } \\
\text { Metastasis } \\
\text { Yes vs no }\end{array}$ & $\begin{array}{l}1.083 \\
(0.475-2.472)\end{array}$ & 0.850 & & \\
\hline
\end{tabular}

related HCC. Univariate and multivariate analysis for RFS is shown in Table 3.

\section{Survival Analysis}

The cumulative 1-, 3-, and 5-year OS rates were 97.1\%, $78.2 \%$, and $67.3 \%$ in patients with AAPR $>0.40$ group, respectively, which were significantly higher than those in the $\mathrm{AAPR} \leq 0.40$ group $(80.2 \%, 54.4 \%$, and $40.1 \%$, respectively) ( $\mathrm{P}<0.001)$ (Figure $1 \mathrm{~A})$. Median OS of patients with AAPR $>0.40$ group in peripheral blood was 48.47 months, which was statistically significantly higher than those with AAPR $\leq 0.40$ group (33.96 months) (48.47 \pm 1.84 months vs $33.96 \pm 2.23$ months, $\mathrm{P}<0.001)$. The cumulative 1-, 3-, and 5-year RFS rates were 86.1\%, $60.2 \%$, and $54.8 \%$ in patients with AAPR $>0.40$ group, 
A

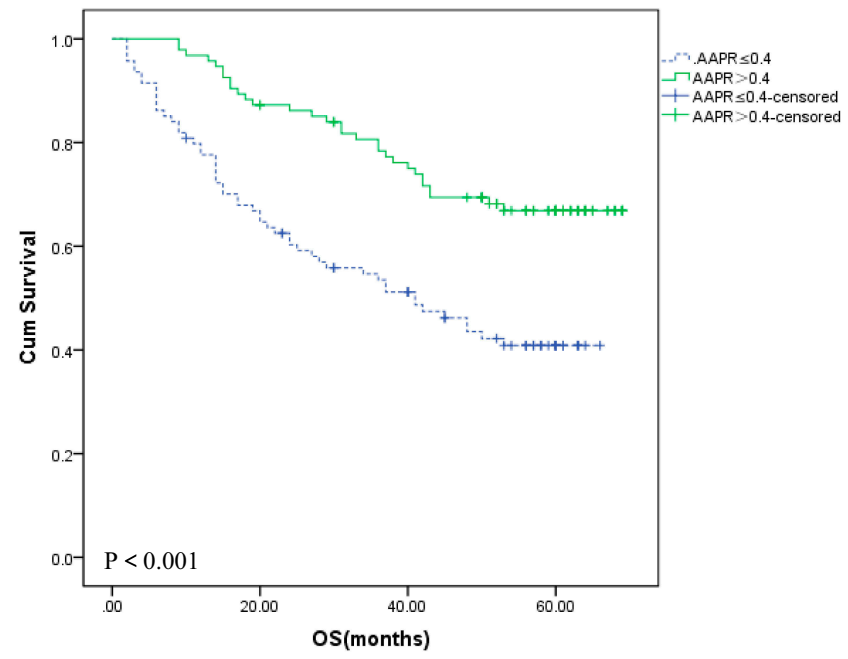

B

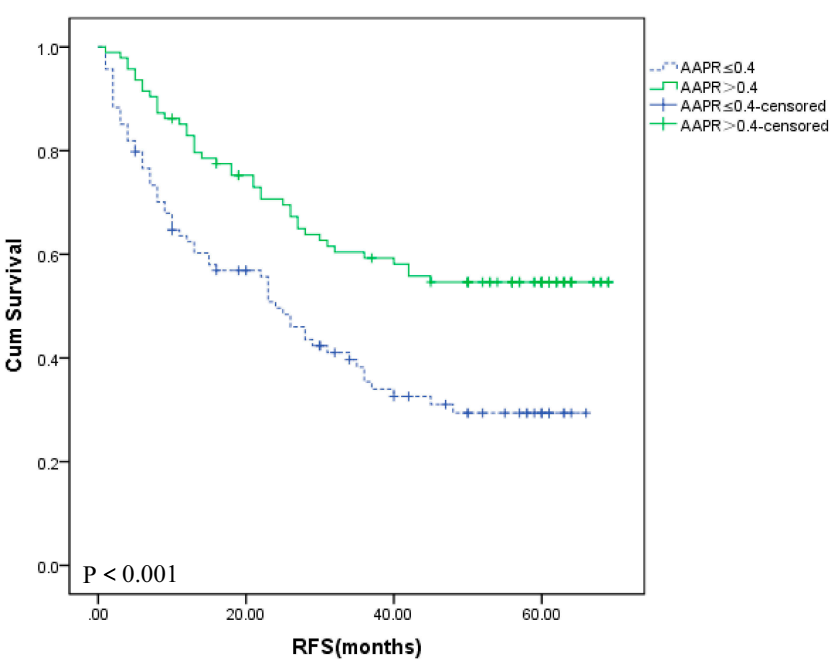

Figure I Overall survival (A) and recurrence-free survival (B) based on the AAPR cutoff point of 0.40 in hepatitis B virus-positive hepatocellular patients.

respectively, which were significantly higher than those in the AAPR $\leq 0.40$ group $(64.7 \%, 38.4 \%$, and $30.2 \%$, respectively) (P<0.001) (Figure 1B). The median RFS of patients with AAPR $>0.40$ group in peripheral blood was 39.12 months, which was statistically significantly higher than those with AAPR $\leq 0.40$ group (24.90 months) (39.12 \pm 2.33 months vs $24.90 \pm 2.13$ months, $\mathrm{P}<0.001$ ).

\section{The Subgroup Analysis of AAPR}

Through subgroup analysis of ascites, we found that AAPR $>0.40$ group provided a better OS (Figure 2A, $\mathrm{P}=0.002$ ) and RFS (Figure 2B, $\mathrm{P}=0.004$ ) for patients without ascites. Furthermore, we found that AAPR $>0.40$ group provided a better median OS (49.92 \pm 1.90 months vs $35.40 \pm 2.46$ months, $\mathrm{P}<0.001)$ and RFS $(41.47 \pm 2.49$ months vs $26.49 \pm 2.38$ months, $\mathrm{P}<0.001)$ for patients without ascites.

The AAPR $>0.40$ group provided a better OS (Figure $3 \mathrm{~A}, \mathrm{P}=0.014$ ) and RFS (Figure $3 \mathrm{~B}, \mathrm{P}=0.036$ ) for patients with ascites. The AAPR $>0.40$ group also had longer median OS (40.80 \pm 5.58 months vs $28.26 \pm 5.11$ months, $\mathrm{P}=0.109)$ and RFS $(26.73 \pm 5.65$ months vs $18.63 \pm 4.58$ months, $\mathrm{P}=0.268$ ) compared to the $\mathrm{AAPR} \leq 0.40$ group for patients with ascites.
A

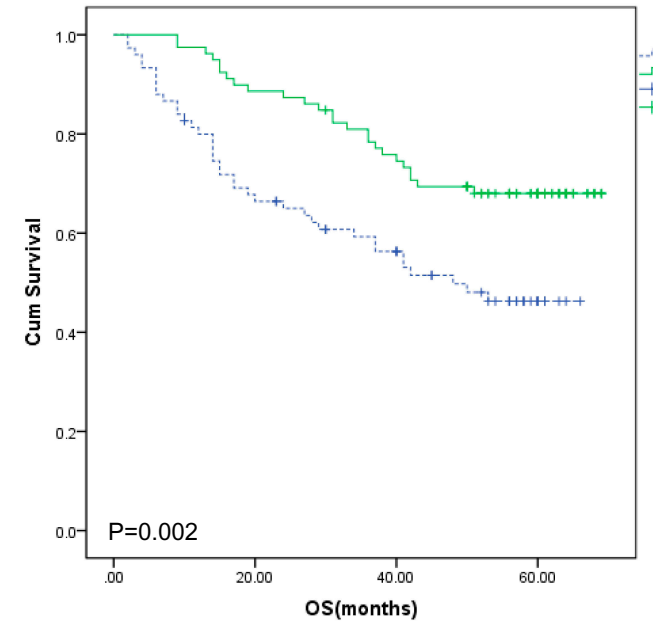

B

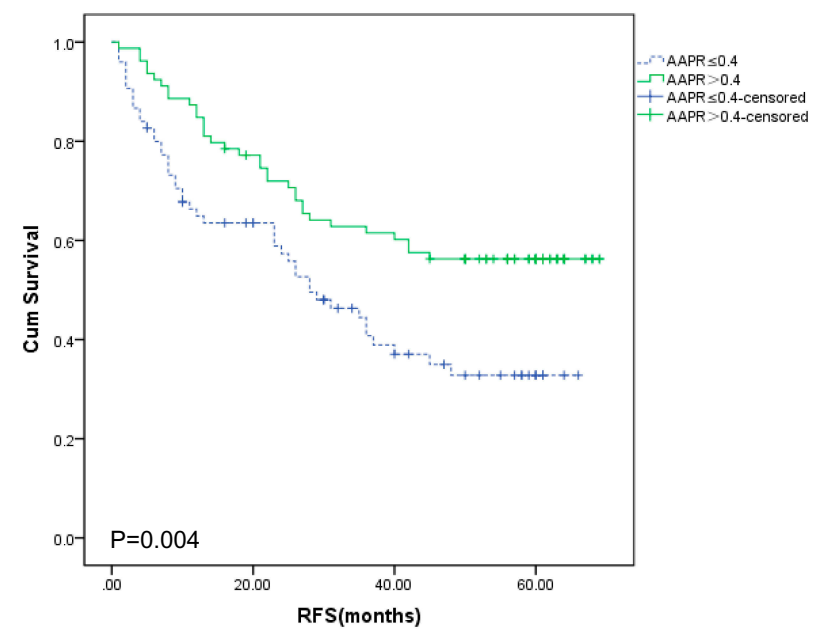

Figure 2 Overall survival (A) and recurrence-free survival (B) in the subgroup of patients without ascites. 
A

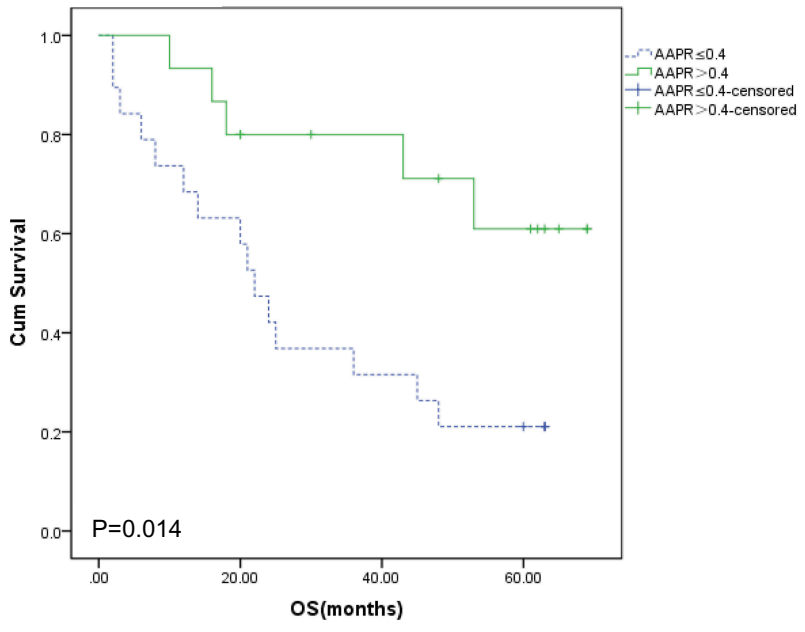

B

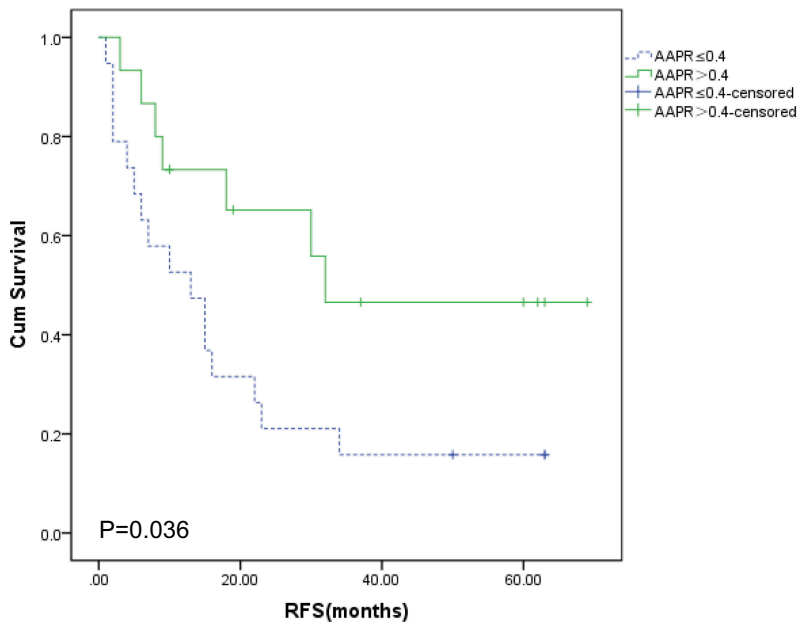

Figure 3 Overall survival (A) and recurrence-free survival $(\mathbf{B})$ in the subgroup of patients with ascites.

\section{Discussion}

Our study aimed to develop better prognostic tools for patients with liver disease caused by chronic hepatitis B infection. We present the first study, through our prior literature review, to analyze the association of AAPR with HBV-related HCC patients undergoing curative resection treatment. Our study explored the prognostic value of the AAPR in HBV-related HCC patients after curative resection and concluded that AAPR was an independent prognostic predictor HBV-related HCC. Furthermore, our results showed that patients with AAPR level under 0.40 have decreased OS and RFS.

Serum ALB and ALP levels are major indexes for liver function examination. Liver function indicators directly associate with the prognosis of HCC patients. Albumin is a globular protein with liver protein synthetic function and also serves as a nutritional index in tests. High serum ALB levels are associated with a low recurrence rate of HCC patients. ${ }^{13}$ The presence of ALB in serum reduces the phosphorylation of $\mathrm{Rb}$ protein and suppresses cellular proliferation of HCC. ${ }^{14}$ ALB could also modulate the systemic and organ inflammatory reaction, which plays an antioxidant role in tumorigenesis. ${ }^{15}$ Recently, ALB has become a popular bio-marker for the prediction of survival in various malignancies, such as colorectal cancer and renal cell carcinoma. ${ }^{16,17}$ Therefore, low ALB levels not only indicates insufficient liver function but reflects a lack of human defense capabilities.

ALP is a hydrolase enzyme presented in all tissues and organs, such as the bile duct and bone, but mainly gathers in the liver. ${ }^{18}$ Cytological study has shown that the nuclear ALP response rate in Hep-G2 cells was about 5 times higher than that in normal cells. ${ }^{19}$ This phenomenon suggests that high levels of ALP might be related to the proliferation of cancer cells. Moreover, ALP is one of the fundamental elements in the Chinese University Prognostic Index systems and considered to be a poor prognostic factor if higher than $200 \mathrm{U} / \mathrm{L}{ }^{20}$ Cumulative data derived from the Asian population with HCC have revealed elevation of ALP was associated with poor outcome. ${ }^{21-23}$ For instance, a large-scale study in Taiwan showed that ALP is an independent factor for DFS and OS. ${ }^{21}$ Carr et al reported that ALP levels were related to HCC extrahepatic metastasis. ${ }^{22}$ Meanwhile, they also reported patients with larger tumors with similar platelet and bilirubin levels had significantly increased ALP and the presence of PVTT. $^{23}$ Thus ALP may play an important role in cell cycle regulation, cell proliferation and tumor formation.

AAPR is an easily obtained biomarker that combines ALB and ALP providing added clinical benefit. Chan et al first proposed the concept of the AAPR and established AAPR was an independent prognostic factor for patients with HCC. ${ }^{11}$ In our study, univariate and multivariate analyses indicated that ALP and ALB were not important independent risk factors for OS or RFS, while AAPR was important. In this study, AAPR (cutoff: 0.40) was used for survival prediction in HBV-related HCC subjects and patients with AAPR below 0.40 were associated with poor prognosis. More importantly, AAPR has been identified as a predictor for clinical outcomes in a variety of malignancies, such as cholangiocarcinoma, ${ }^{18}$ upper tract urothelial carcinoma, ${ }^{24}$ and metastatic nasopharyngeal carcinoma. ${ }^{25}$

In our study, ascites, fluid build-up in abdomen, was determined as a significant independent prognostic factor 
of RFS. The results were consistent with research findings showing ascites were independent predictors of poor survival. ${ }^{26}$ Regardless of whether patients had ascites or not, AAPR $>0.40$ group had longer OS and RFS. However, for some patients with ascites, the comparison of median OS and RFS between AAPR $>0.40$ group and AAPR $\leq 0.40$ group was not statistically significant. This may be related to fewer patients with ascites in our study.

Our study has several strengths that would support changes to diagnoses and treatment based on our findings. First, to our knowledge, this is the first study focusing on verifying the prognostic potential of AAPR in HBVrelated HCC undergoing surgery. Second, AAPR is a readily available indicator in clinical practice. Moreover, the association of AAPR and other clinicopathological characteristics was explored in this study. Last, all enrolled patients were treated with curative resection, which to a large extent, minimized the potential influence from the different treatment options.

Although our study was the first to explore the prognosis value of AAPR in HBV-related HCC patients treated by liver resection, we have identified several limitations requiring further study. Firstly, the study design had inevitable withdrawal of certain patients from the selection process and created a clinical bias due to the retrospective nature of the study. Secondly, all of the data were collected from a single medical center and our sample size was still limited. Thirdly, the results of the present study were limited to patients to HBV-associated HCC. In the future, multicenter and prospective clinical studies with a large sample size are urgently needed to confirm our conclusions and promote the clinical application of AAPR.

\section{Conclusion}

Overall, our results suggest AAPR is a promising and reliable prognostic indicator in patients with $\mathrm{HBV}$-related HCC after hepatic resection. This indicator can be used as a routine examination of HBV-related HCC patients before surgery, and it will help clinicians adopt personalized adjuvant therapies for patients with $\mathrm{HCC}$ that are at high risk for recurrence after liver resection.

\section{Abbreviation}

AAPR, Albumin-to-alkaline phosphatase ratio; HBV, Hepatitis B virus; HCV, Hepatitis C virus; HCC, hepatocellular carcinoma; ALP, alkaline phosphatase; ALB, albumin; TB, total bilirubin; ALT, alanine aminotransferase; GGT, glutamyl transpeptidase; AFP, alpha-fetoprotein.

\section{Acknowledgment}

This study was supported by National Natural Science Foundation of China (81871700 and 81902349) and Natural Science Foundation of Shandong Province (ZR2019MH005).

\section{Disclosure}

The authors report no conflicts of interest in this work.

\section{References}

1. Torre LA, Bray F, Siegel RL, Ferlay J, Lortet-tieulent J, Jemal A. Global cancer statistics, 2012. CA Cancer J Clin. 2015;65(2):87-108. doi:10.3322/caac. 21262

2. Yuan JM, Govindarajan S, Arakawa K, Yu MC. Synergism of alcohol, diabetes, and viral hepatitis on the risk of hepatocellular carcinoma in blacks and whites in the U.S. Cancer. 2004;101 (5):1009-1017. doi:10.1002/cncr.20427

3. Poon D, Anderson BO, Chen LT, et al. Management of hepatocellular carcinoma in Asia: consensus statement from the Asian Oncology Summit 2009. Lancet Oncol. 2009;10(11):1111-1118. doi:10.1016/ S1470-2045(09)70241-4

4. Bruix J, Sherman M. Management of hepatocellular carcinoma: an update. Hepatology. 2011;53(3):1020-1022. doi:10.1002/hep.24199

5. Cheng Z, Yang P, Qu S, et al. Risk factors and management for early and late intrahepatic recurrence of solitary hepatocellular carcinoma after curative resection. HPB. 2015;17(5):422-427. doi:10.1111/ hpb. 12367

6. Hong YF, Chen $\mathrm{ZH}$, Wei L, et al. Identification of the prognostic value of lymphocyte-to-monocyte ratio in patients with HBV-associated advanced hepatocellular carcinoma. Oncol Lett. 2017;14(2):2089-2096. doi:10.3892/ol.2017.6420

7. Lin WF, Zhong MF. Prognostic role of platelet-to-lymphocyte ratio in hepatocellular carcinoma with different BCLC stages: a systematic review and meta-analysis. Gastroenterol Res Pract. 2018;2018:5670949. doi:10.1155/2018/5670949

8. Gomez D, Farid S, Malik HZ, et al. Preoperative neutrophil-tolymphocyte ratio as a prognostic predictor after curative resection for hepatocellular carcinoma. World J Surg. 2008;32(8):1757-1762. doi:10.1007/s00268-008-9552-6

9. Cai X, Chen Z, Chen J, et al. Albumin-to-alkaline phosphatase ratio as an independent prognostic factor for overall survival of advanced hepatocellular carcinoma patients without receiving standard anti-cancer therapies. $J$ Cancer. 2018;9(1):189-197. doi:10.7150/ jca. 21799

10. Chen ZH, Zhang XP, Cai XR, et al. The predictive value of albumin-to-alkaline phosphatase ratio for overall survival of hepatocellular carcinoma patients treated with trans-catheter arterial chemoembolization therapy. $J$ Cancer. 2018;9(19):3467-3478.

11. Chan AW, Chan SL. Albumin-to-alkaline phosphatase ratio: a novel prognostic index for hepatocellular carcinoma. Dis Markers. 2015;2015:564057. doi:10.1155/2015/564057

12. Camp RL, Dolled-filhart M, Rimm DL. X-tile: a new bio-informatics tool for biomarker assessment and outcome-based cut-point optimization. Clin Cancer Res. 2004;10(21):7252-7259. doi:10.1158/1078-0432.CCR-04-0713

13. Hiraoka A, Kumada T, Nouso K, et al. Proposed new sub-grouping for intermediate-stage hepatocellular carcinoma using albumin-bilirubin grade. Oncology. 2016;91(3):153-161. doi:10.1159/000447061

14. Nojiri S, Joh T. Albumin suppresses human hepatocellular carcinoma proliferation and the cell cycle. Int J Mol Sci. 2014;15(3):5163-5174. doi:10.3390/ijms 15035163 
15. Arroyo V, Garcia-martinez R, Salvatella X. Human serum albumin, systemic inflammation, and cirrhosis. $J$ Hepatol. 2014;61 (2):396-407. doi:10.1016/j.jhep.2014.04.012

16. Nazha B, Moussaly E, Zaarour M, Weerasinghe C, Azab B. Hypoalbuminemia in colorectal cancer prognosis: nutritional marker or inflammatory surrogate? World J Gastrointest Surg. 2015;7 (12):370-377. doi:10.4240/wjgs.v7.i12.370

17. Chen Z, Shao Y, Fan M, et al. Prognostic significance of preoperative C-reactive protein: albumin ratio in patients with clear cell renal cell carcinoma. Int J Clin Exp Pathol. 2015;8(11):14893-14900.

18. Xiong JP, Long JY, Xu WY, et al. Albumin-to-alkaline phosphatase ratio: a novel prognostic index of overall survival in cholangiocarcinoma patients after surgery. World J Gastrointest Oncol. 2019;11 (1):39-47. doi:10.4251/wjgo.v11.i1.39

19. Yamamoto K, Awogi T, Okuyama K, Takahashi N. Nuclear localization of alkaline phosphatase in cultured human cancer cells. Med Electron Microsc. 2003;36(1):47-51. doi:10.1007/s007950300006

20. Leung TW, Tang AM, Zee B, et al. Construction of the Chinese University Prognostic Index for hepatocellular carcinoma and comparison with the TNM staging system, the Okuda staging system, and the Cancer of the Liver Italian Program staging system: a study based on 926 patients. Cancer. 2002;94(6):1760-1769. doi:10.1002/ cncr. 10384
21. Yu MC, Chan KM, Lee CF, et al. Alkaline phosphatase: does it have a role in predicting hepatocellular carcinoma recurrence? J Gastrointest Surg. 2011;15(8):1440-1449. doi:10.1007/s11605011-1537-3

22. Carr BI, Guerra V. Hepatocellular carcinoma extrahepatic metastasis in relation to tumor size and alkaline phosphatase levels. Oncology. 2016;90(3):136-142. doi:10.1159/000443480

23. Carr BI, Guerra V. Hepatocellular carcinoma size: platelets, gamma-glutamyl transpeptidase, and alkaline phosphatase. Oncology. 2013;85(3):153-159. doi:10.1159/000354416

24. Tan P, Xie N, Ai J, et al. The prognostic significance of albumin-toalkaline phosphatase ratio in upper tract urothelial carcinoma. Sci Rep. 2018;8(1):12311. doi:10.1038/s41598-018-29833-5

25. Nie M, Sun $P$, Chen C, et al. Albumin-to-alkaline phosphatase ratio: a novel prognostic index of overall survival in cisplatin-based chemotherapy-treated patients with metastatic nasopharyngeal carcinoma. J Cancer. 2017;8(5):809-815. doi:10.7150/jca.17536

26. Hsu CY, Lee YH, Huang YH, et al. Ascites in patients with hepatocellular carcinoma: prevalence, associated factors, prognostic impact, and staging strategy. Hepatol Int. 2013;7(1):188-198. doi:10.1007/ s12072-011-9338-z

\section{Publish your work in this journal}

OncoTargets and Therapy is an international, peer-reviewed, open access journal focusing on the pathological basis of all cancers, potential targets for therapy and treatment protocols employed to improve the management of cancer patients. The journal also focuses on the impact of management programs and new therapeutic agents and protocols on patient perspectives such as quality of life, adherence and satisfaction. The manuscript management system is completely online and includes a very quick and fair peer-review system, which is all easy to use. Visit http://www.dovepress.com/ testimonials.php to read real quotes from published authors. 